\title{
Challenges in participation
}

\section{Users and their roles in the development of home-based Pervasive Healthcare applications}

\author{
Rikke Aarhus, Erik Grönvall, Morten Kyng \\ Department of Computer Science \\ Aarhus University \\ Aarhus, Denmark \\ \{raa, gronvall, mkyng\}@cs.au.dk
}

\begin{abstract}
Participatory Design (PD) has a strong tradition in professional settings, including e.g. hospitals and nursing homes. As care and rehabilitation practices move, to a greater extent, out of the hospitals and into private homes a new take on PD is needed to facilitate design activities with patients or laypeople as the primary user groups and to design healthcare applications to be used primarily in the home. This paper discusses challenges and possibilities related to the design of home-based healthcare applications and especially the users' possibilities for participation in creative PD activities. Based upon ongoing design-work, related to home-based rehabilitation of elderly suffering from vestibular dysfunction (dizziness), this paper presents lessons learned and initial outcomes related to patient/citizen-focused development of healthcare solutions for private homes. We present initial ideas on how PD can be used to develop pervasive healthcare applications with less resourceful user-groups such as elderly people suffering from illness.
\end{abstract}

Keyword - participatory design; rehabilitaiton; elderly; homebased healthcare; non-professional users and settings.

\section{INTRODUCTION}

In the western societies, ongoing trends are that patients spend less time at the hospital and that healthcare expertise and treatment are centralized. Furthermore, an increase of chronic diseases can be identified. These trends put a focus on homecare and a more active patient role, including increased selfcare. To answer to this emergent need of home-based care, participatory design (PD) activities have been used by researchers together with for example pregnant women [1] and elderly undergoing stroke rehabilitation [2].

This paper describes experiences using PD in an ongoing project that aims to provide assistive tools to support elderly affected by vestibular dysfunction in their home-based rehabilitation activities. The methods and approach of PD are challenged by the user group due to their illness and ageing together with the focus on the home. Indeed, user participation when designing healthcare solutions together with patients can be challenging, due to the fact that the users are patients suffering from illness. Hence, as the illness becomes more critical, time-consuming and/or physically and mentally tiresome for the patients, they have fewer resources left to engage in design activities around support technologies. With chronic diseases, it is not an option to await recovery to include

Permission to make digital or hard copies of all or part of this work for personal or classroom use is granted without fee provided that copies are not made or distributed for profit or commercial advantage and that copies bear this notice and the full citation on the first page. To copy otherwise, to republish, to post on servers or to redistribute to lists, requires prior specific permission and/or a fee.

PERVASIVEHEALTH 2010, March 22-25, Munchen, Germany

Copyright $\odot 2010$ ICST 978-963-9799-89-9

DOI 10.4108/ICST.PERVASIVEHEALTH2010.8794 ex-patients in the PD process, so user involvement will include ill people. Furthermore, as will be discussed in section 3, challenges can emerge when working not only with ill instead of healthy users, but working with ill people in their private homes. The physical and mental picture our elderly have of their homes requires delicacy in our approach and naturally puts a focus on aesthetical properties of our support systems.

\section{CASE DESCRIPTION}

We have carried out design work with elderly people, (aged $65+$ ), affected by vestibular dysfunction, an inner-ear problem causing vertigo. They all undergo a four-month rehabilitation at a specialized fall-clinic. They are all screened to be free from e.g. dementia and other cognitive problems before admitted to the program. However, they may suffer from age-related problems such as bad hearing, tiredness and muscular weakness. The elderly citizens come to the clinic twice a week for supervised rehabilitation training together with two physiotherapists also participating in our project and three to four other patients enrolled in the rehabilitation program. The training at the clinic consists of vestibular exercises (e.g. eye exercises) (see Fig. 1), balance training (e.g. walk on wooden boards) and weight training (e.g. dumbbells) that are progrediated with time.

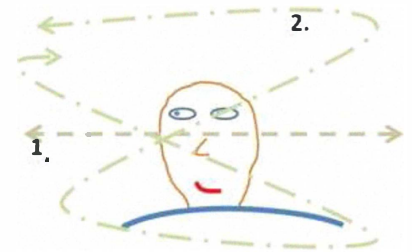

Figure 1: Eye exercises: 1) Horizontal eye-movement. 2) Combined horizontal and vertical eye-movement.

Besides from the training at the clinic, the elderly people are to make exercises at home until they experience dizziness, preferably twice a day. The home exercises are primarily the vestibular eye-exercises also carried out at the clinic. In the beginning, the elderly might have to lie down or sit in a chair while performing the exercises. Later, the elderly are instructed to place themselves in a corner, with a chair in front of them (this creating a fall-preventing environment) as they perform 
the exercises standing up. This progression follows each patient's balance-improvement as a result of the rehabilitation. After the four-month rehabilitation period, the elderly citizens should continue with the home-exercises to avoid recurrence. Field studies (see below) showed that many of the elderly people face difficulties with the home-exercises. Reasons for this were difficulties in doing the exercises correctly, little understanding of the importance of the exercises and little motivation among some of the elderly.

\section{Assistive HeAlTh TECHNOLOGIES}

There is a long tradition in Scandinavia of including endusers in the complete design cycle of new computer aided systems [3]. This tradition developed partly as a reaction to the User-Centred Design (UCD) paradigm where a user only partially takes part in the design process [4], usually in the role of requirements provider. Bannon examines these two viewpoints in [5] where he talks about a shift from UCD to User-Involved Design [3]. Within the field of User-Involved design, early work such as Utopia $[6,7]$ developed into what today is known as Participatory Design (PD). One can argue that while engaging in UCD you design for the users, while in PD you design with the users. This perspective is however challenged in recent research $[8,9]$, where projects have explored settings were some of the users have had problems participating on equal terms together with the design-team and other stakeholders. Such users were e.g. pre-mature born babies or elderly with dementia. Here, under the participatory design umbrella, a mixture of design for and design with has been applied to align an outcome with all the stakeholders' requirements. E.g. doctors and therapists have engaged in PD activities related to the care of preterm children, and the children have (passively) been informing the process by creating requirements based on their delicate conditions and medical needs. Others, e.g. Bertelsen et al. [10] have identified the need to understand what it means to do PD in non-work settings with ill or weak users, but little research have actually been reported concerning PD studies within home-based healthcare, and even fewer that acknowledge the challenge of how to include ill or other disadvantaged users.

We will now describe some general conditions and challenges related to having a PD activity with non-healthy users in private homes.

\section{A. The patient}

The patient role changes as the patient moves between hospital and the home. At the hospital, the patient only has to care about being 'a patient', while at home, 'the patient' shall also be e.g. husband/wife, sportsman, neighbor [11].

\section{B. The patients' home}

Even if studies have shown that patients in some cases experience a higher sensation of 'quality of life' during homecare compared to hospitalization [12], known barriers exist. It is challenging to transfer a hospital-based treatment directly to a home-setting, due to the several unique properties of the settings. Indeed, the home as such is not designed as a place for care, neither from a potential care provider nor from a patient perspective. Furthermore, people often prefer to keep their sickness invisible in their homes [13]. This diversity in settings together with differences in the layout of the homes (each home being different in size while also furmished and 'personalized' in an individualized manner) and in habits, personality and life situation of the inhabitant (including their diverse family situations) challenge a successful implementation of homebased healthcare applications.

\section{Technology}

Technology in itself poses challenges to the success of home-based treatment. While some technologies are frequently recognized as 'empowering' for the patients [14], patients (especially elderly) may also feel alienated by the technology [15]. Technology (e.g. applications, interfaces and the infrastructure) used in home-care situations must answer to a broad list of both hard and soft requirements existing in private homes. Technological healthcare systems for the home must not only fulfill requirements from a medical protocol but also a wider range of requirements emerging from the setting (i.e. the home) and its inhabitants.

\section{Healthcare sector}

Assistive technologies supporting everyday home-care should respond to a number of health protocols while providing meaningful support for the patients and healthcare professionals. Assistive technology for home-based care must also be seen from a healthcare and administrative perspective; what is the role of for example the doctor, physiotherapist or home-visiting nurse in the setup, configuration, administration and monitoring of e.g. use, alarm situations and collected data?

\section{PARTICIPATORY DESIGN FOR HOME-BASED REHABILITATION}

In this section, we describe what we have done to understand and involve the users in the design of technology to support vestibular home-exercises. We highlight several challenging factors in our PD process and discuss reasons for and solutions to these challenges.

Initially, we conducted a field study to get an understanding of what is at stake in the existing rehabilitation program. The field study was carried out in the home of the elderly and at the clinic, i.e. the places of rehabilitation, and consisted of interviews and observations. It directed our focus to the homebased rehabilitation and gave insights into the daily life of these elderly people and the conditions for doing home-exercises. After the field study, we held a future workshop [16] with the project partners and users at the hospital. A more technologyoriented workshop, held in our lab, followed where elderly people tried different mock-ups and simple prototypes to facilitate a discussion on technologies for home-based rehabilitation. In addition to these workshops we have carried out a number of iterative PD activities in the homes of elderly people attending the rehabilitation program and at the clinic (see Fig. 2). In the homes, the focus has been on situating the development process in the setting where the technology is to be used. The activities with the patients in their homes have varied from more interview-like to experimenting with mock ups/prototypes. The activities at the clinic have been twofold: creative sessions with the physiotherapists and sessions centred 
on prototypes during the regular training with the participation of both physiotherapists and the patients.

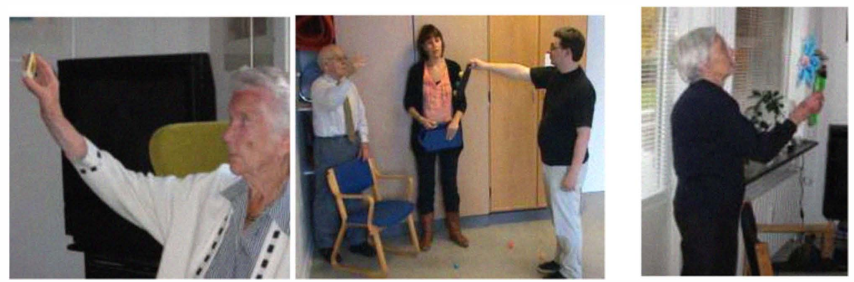

Figure 2: (left) Home exercises without technology. (Middle) PD dart activity at the clinic. (Right) PD flower activity in the home.

\section{A. Challenges for Participatory Design for home-based rehabilitation}

Looking back, the participatory design process in this project has not, so far, been as successful as we would have hoped from a patient-involvement perspective. We have found it difficult to foster the creative approach and reflection that we have experienced in other projects. We have identified several factors that have challenged the process. These are described below.

One such factor is that the elderly themselves have not identified a need for improvement. While some of the elderly recognized the home-exercises to be difficult and that they lacked motivation, they did not consider this a problem to be dealt with, nor have our project related work made them reflect on this. The physiotherapists initially believed that the homeexercises were carried out as described, but have changed their beliefs, practices and behaviour as a result of the design process. Thus in relation to them PD is a much greater success.

Secondly, our main users, i.e. the elderly people, suffer from a condition that in different degrees affect their mental and physical capacity and energy - and this also influenced the PD process. Long creative sessions have not been possible and furthermore, their condition changes from day to day, so we had to adjust our activities to the current feeling of the elderly person. In addition, the elderly people are geriatric patients who often suffer from several conditions at a time.

Thirdly, from the field studies we learned that many of the elderly people deliberately try not to let their disease be what their life revolves around at home, this is the case only at the hospital. Bringing our design activity with its focus on the disease into the home, we might cause de-motivation to participate actively amongst the elderly.

Fourth, the elderly users' initial perception of technology has affected our design process. We have informed our users that our aim is to develop technological solutions for the hometraining. However, the general understanding of technology among the users has been limited to e.g. a stationary computer invading the home and being difficult to use. However, elderly people are as heterogeneous as a group as is the rest of the population. Talking about technology, Johanne, 92 years old, explains: "I skip the latest development (...) no, I'm not to begin to, how to explain it, develop my knowledge on this topic. I'm too old". Mie, who is also in her 90 s, on the other hand, cannot live without her mobile phone or her VHS. While there are differences in perception and use, we have, however, experienced that the majority of the involved users have a rather traditional understanding of technology challenging their involvement in the design process.

Fifth, designing for the home is, as mentioned, different from e.g. designing for a professional setting. The different purposes of a home and the different roles of the inhabitants may affect the potential technology use in the home. In our experience the elderly enrolled in the rehabilitation are in general not keen on devoting much physical space in their home for the home-exercises. Reasons for this are that their homes are filled with a life-time of furniture and decorations, and that a home often has certain meanings [17] which are frequently more about relaxation than training. Assistive technology for the home must not only be functionally and flexible, but also aesthetically fit into the lives of the elderly.

In our project we have not been able to work with the same group of patients throughout the project. Hence, it has primarily been the physiotherapists and us that have driven the process forward. We have worked with several different elderly people over time which have ensured a wide base of users but which have also challenged the process. For instance, it has limited our possibilities to support creativity, and to 'dig deeper' in the possible solution space, helping the elderly participants to see beyond the obvious and create a richer design experience. We found it difficult to obtain commitment from the elderly for ongoing participation as opposed to the physiotherapists who could devote work time. The elderly people participated voluntarily and their participation depended to a large extent on their interest in the project, what other plans they had, and how they felt. Doing PD with non-professional users in a non-professional setting, issues and activities related to everyday life thus play a large role.

\section{B. The nature of users' participation}

Usually, in PD users participate throughout the design process together with the researchers and designers. Reflecting on the nature of the participation of our users in this particular case, we find that the participation differs from this ideal when focusing on the elderly users (see Fig. 3).

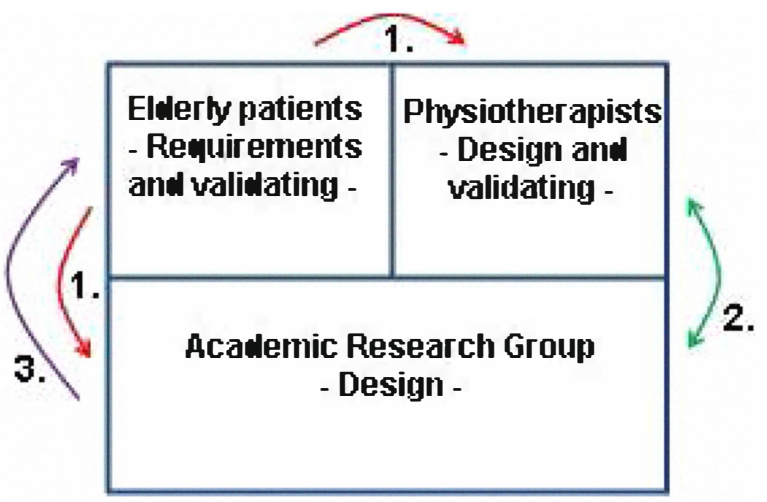

Figure 3: Roles and division of work occurring in parallel throughout the project; $1=$ requirements and feedback, $2=$ Iterative PD work, $3=$ Concepts and prototypes for evaluation. 
Primarily, what we have from the user involvement is an understanding (even if not always spoken out loud) of what the elderly do not like to have, what their physical capabilities are and which therapeutic tools we can introduce into their homes with a reasonable chance of acceptance. We have experienced difficulties in making the elderly users reflect on what they would like to have rather than what they do not like to have. However, the physiotherapists' participation has developed into being creative and reflective bringing ideas forth, e.g. a dart game, that we together have worked with. While we to a large extent design with the physiotherapists, we to a larger extent design for the elderly.

\section{DISCUSSION}

Our user-groups did not have the resources to fully engage in PD activities such as technology explorations, mock-ups, Wizard of $\mathrm{Oz}$ and different forms of creative workshops. However, our findings confirm that even with user-groups whose involvement in PD is as difficult as in our project, their contribution clearly adds to the quality of the results and are likely to be essential for the acceptance of our designs. The elderly in our project represent users that have not participated (so far) in the design work on equal terms with the therapists and the academic researchers. Not due to hieratical or powerstructures but rather due to their capabilities [10].

Little research related to PD in the home exists, and less with people suffering from illness. Our aim is to develop technologies that support both patients and therapists in conducting and managing home-based rehabilitation regimes. Our early results indicate that, for our elderly users, the home as such and the attributes given to the home by our users (being a place for non-sickness) create further limitations on our users' engagement in illness-related activities in the home. Still, aligned with the tradition to capture user experiences insitu our findings show that the home as a place for development is fundamental to understand the context, its inhabitants and values. Furthermore, the home offers the possibility to evaluate concepts and prototypes in their intended use-domain. We still have to understand how to overcome the limitations related to home-based activities with this group of users; usually, complete solutions and applications are introduced as late as possible in a design process, not to limit or 'lock in' the creative process early on. Still, one possible way to enable the elderly to be, in some sense, creative about their situation and rehabilitation program could be to use the results we now have in prototypes as springboards into more open, creative design activities including the elderly. If we can show, through prototypes that to a large extend answers to their requirements make the training more engaging and motivating, the idea is that they will be better prepared to enter a creative design cycle together with us. If possible, a challenge will be to present these prototypes in a way that opens up, and not closes the design space for our elderly project partners.

\section{ACKNOWLEDGMENT}

We like to thank the elderly and the physiotherapists, who participate in the project on home-based VR. We also like to thank the Consortium User driven Healthcare Innovation and the Danish Agency for Science, Technology and Innovation. Lastly, we would like to thank Simon Bo Larsen from the Alexandra Institute for his valuable work on the project.

\section{REFERENCES}

[1] R. Aarhus, S. Ballegaard, and T. Hansen, "The eDiary: Bridging home and hospital through healthcare technology," in Proceedings of the Eleventh European Conference on Computer-Supported Cooperative Work, Vienna, Austria, 2009, pp. 63-83.

[2] L. Axelrod, G. Fitzpatrick, J. Burridge et al., "The reality of homes fit for heroes: design challenges for rehabilitation technology at home," Journal of Assistive Technologies, vol. 3, no. 2, pp. 9, June 2009, 2009.

[3] G. Bjerknes, P. Ehn, and M. Kyng, Computers and democracy: a Scandinavian challenge, Aldershot, England: Avebury, Gower Publishing Company Ltd., 1987.

[4] D. A. Norman, and S. W. Draper, User Centered System Design; New Perspectives on Human-Computer Interaction: Lawrence Erlbaum Associates, Inc. Mahwah, NJ, USA, 1986.

[5] L. Bannon, "From human factors to human actors: the role of psychology and human-computer interaction studies in system design," Design at work: cooperative design of computer systems, J. Greenbaum and M. Kyng, eds., pp. 25-44: Lawrence Erlbaum Associates, Inc. Mahwah, NJ, USA, 1992.

[6] S. Bødker, P. Ehn, J. Kammersgaard et al., "A Utopian Experience," Proceedings of the 1986 Conference on Computers and Democracy, pp. 251-278, 1987

[7] S. Bødker, P. Ehn, D. Sjögren et al., "Co-operative Designperspectives on 20 years with 'the Scandinavian IT Design Model'," in Proceedings of NordiCHI 2000, Stockholm, Sweden, 2000, pp. 22-24.

[8] E. Grönvall, L. Piccini, A. Pollini et al., "Assemblies of Heterogeneous Technologies at the Neonatal Intensive Care Unit," in European Conference on Ambient Intelligence, Darmstadt, Germany, 2007.

[9] P. Marti, and L. Giusti, "Coupling the Digital and the Physical in Therapeutic Environments," Lecture Notes in Computer Science, vol. 4551, pp. 1173, 2007.

[10] O. Bertelsen, and P. Hedvall, "New Challenges for Participation in Participatory Design in Family, Clinical and Other Asymmetrical, Nonwork Settings," in Interact 2009, The 12th IFIP TC 13 International Conference on Human-Computer Interaction: Part II, Uppsala, Sweden, 2009, pp. 971-972.

[11] A. Alonzo, "Everyday illness behavior: a situational approach to health status deviations," Social science \& medicine, vol. 13, no. 4, pp. 397 , 1979.

[12] C. Coley, Y. Li, A. Medsger et al., "Preferences for home vs hospital care among low-risk patients with community-acquired pneumonia," Archives of Internal Medicine, vol. 156, no. 14, pp. 1565, 1996.

[13] S. A. Ballegaard, T. R. Hansen, and M. Kyng, "Healthcare in everyday life: designing healthcare services for daily life," in Proceeding of the twenty-sixth annual SIGCHI conference on Human factors in computing systems, Florence, Italy, 2008, pp. 1807-1816.

[14] E. D. Mynatt, J. Rowan, S. Craighill et al., "Digital family portraits: supporting peace of mind for extended family members," in Proceedings of the SIGCHI conference on Human factors in computing systems, Seattle, Washington, United States, 2001.

[15] N. Johannsen, and F. Kensing, "Empowerment reconsidered," in Proceedings of the 4th decennial conference on Critical computing: between sense and sensibility, Aarhus, Denmark, 2005.

[16] R. Jungk, and N. Müllert, "Future workshops How to create desirable futures," Institute for Social Inventions, London, 1987.

[17] A. Williams, "Changing geographies of care: employing the concept of therapeutic landscapes as a framework in examining home space," Social science \& medicine, vol. 55, no. 1, pp. 141-154, 2002. 